\title{
Flow structure around an actual willow patch under different depth conditions
}

\author{
Chanjoo Lee ${ }^{1}$, Donggu $\mathrm{Kim}^{1}$, Sungjung $\mathrm{Kim}^{1}$, Un $\mathrm{Ji}^{2}$, Jihyun $\mathrm{Kim}^{1}$, Dongwoo $\mathrm{Ko}^{1}$ \\ ${ }^{1}$ Korea Institute of Civil Engineering and Building Technology, Goyang-si, Gyeonggi-do, 10223, \\ Republic of Korea \\ ${ }^{2}$ Korea Institute of Civil Engineering and Building Technology / Korea University of Science and \\ Technology, Goyang-si, Gyeonggi-do, 10223, Republic of Korea
}

\begin{abstract}
Vegetation is one of the key factors in river management where environmental aspects as well as flood protection should be taken into consideration. Because of this, numerous studies have been done including experiments and hydrodynamic modelling. Because most of experimental studies were made in indoor laboratory flumes with artificial trees, there are still limitations in transfer of their result to actual channels. REC (River Experiment Center) of Korea has been operating three real-scale, nature-like outdoor experimental channels. In a straight channel, several $4 \times 2 \mathrm{~m}$ actual willow patches were planted and have been grown last three years for studies on flow vegetation interaction. A set of intensive flow measurement was made around the first upstream willow patch using ADVs together with measurement of vegetation properties. The experiments were made under several different depth conditions simulating snow-melt and flash-flood. Distribution of flow around and through the patch was characterized along with vertical profiles. The results of the experiment enhance understanding on interaction of flow and actual vegetation in a natural channel and may also provide information on flow resistance used for hydrodynamic modelling and validation.
\end{abstract}

\section{Introduction}

Recently, vegetation is considered as one of the key factors in river management where environmental and aesthetic aspects as well as flood protection should be taken into consideration. Furthermore, riparian vegetation plays an active role in channel forming processes $[1,2]$ by acting a roughness element to cause sedimentation and island building and increasing bank stability. Because of this, numerous studies have been done to describe flow characteristics by experiments and hydrodynamic modelling [3-6].

Among the experimental studies, most were conducted along indoor laboratory flumes with artificially manufactured trees. Though actual trees were used in some study, experiment itself is hard to reproduce actual condition of real stream. Thus there are still limitations when their results are transferred to natural channel conditions. It comes from not only scale problem, but also different vegetation and flow conditions between experimental and real channel. In this study, we used nearly real-sized, nature-like flume and measured flow characteristics around an actual willow patch. In doing the experiment, we adopted two flow 
conditions simulating snow-melt and flash-flood were given along the real willow vegetation which is also subject to change during experiment period.

The result presented in this paper is a part of the results of RIED2017 (REC International Experiment Days) which is a collaborative experiment campaign carried out along the realscale experimental channel of River Experiment Center in Korea. This paper briefly provided some results of flow measurement around a vegetation patch.

\section{Large-scale outdoor flume and experimental conditions}

Large-scale experiments for vegetated flows have been performed in the KICT-REC (Korea Institute of Civil Engineering and Building Technology - River Experiment Center) located in Andong of South Korea. KICT-REC is designed for prototype tests with three full scale channels (600 $\mathrm{m}$ long and $11 \mathrm{~m}$ wide) as shown in Figure 1 and maximum flow rate generated by large capacity pumps is about $10 \mathrm{~m}^{3} / \mathrm{s}$.

The channel section with a $60 \mathrm{~m}$ long stretch, a trapezoidal cross-section of $3 \mathrm{~m}$ bottom width and $11 \mathrm{~m}$ top width, and a bank slope of $1: 1.5(\mathrm{~V}: \mathrm{H})$ was used for this study and a bed slope of the channel section was 1/1,000. The median size of bed materials was about $1 \mathrm{~mm}$. Young willow saplings were planted in October 2014 to form the alternative bar shape of vegetation patches of $4 \mathrm{~m}$ long and $1.5 \mathrm{~m}$ wide and the experiments were performed in September 2017 (Fig. 2). Target patch for flow measurement was the first one among 7 patches as shown in Figure 2. The diameter of stems for rooted willows ranged $1.15 \mathrm{~cm}$ to $4.5 \mathrm{~cm}$, the number of stems per square meter was 14.8, and the mean height of vegetation was $1.0 \mathrm{~m}$ to $1.4 \mathrm{~m}$ for the $1^{\text {st }}$ patch.

Two different imitated hydraulic conditions such as snowmelt and flash flood hydrographs were applied for the experiments (Table 1, Fig. 2). Snowmelt hydrograph in which gradual falling limb occurs after gentle peak discharge is artificially reproduced by four step of different discharges (S1-S4). Flash flood in which sharp peak is followed by more rapid decrease in discharge is also mimicked using five steps of decrease (F1-F5). Though actual flow showed some discrepancy with designed target hydrographs (gray lines), flow discharge (green lines) was controlled to match them as far as possible. During each step, flow was regulated to maintain steady state for stable measurements. During the largescale experiment, flow velocity was measured by ADVs and LSPIV. Water surface levels were observed with ultrasonic water level sensors and a side looking acoustic Doppler current meter.

Table 1. Flow characteristics of two experiment conditions

\begin{tabular}{|c|r|r|r|r|r|r|r|r|r|}
\hline Condition & \multicolumn{4}{|c|}{ Snowmelt (48 hrs) } & \multicolumn{5}{c|}{ Flash flood (60 hrs) } \\
\hline Case & \multicolumn{1}{|c|}{ S1 } & \multicolumn{1}{|c|}{ S2 } & \multicolumn{1}{|c|}{ S3 } & \multicolumn{1}{|c|}{ S4 } & F1 & \multicolumn{1}{c|}{ F2 } & \multicolumn{1}{|c|}{ 3 } & \multicolumn{1}{c|}{ F4 } & \multicolumn{1}{c|}{ F5 } \\
\hline Discharge $\left(\mathrm{m}^{3} / \mathrm{s}\right)$ & 5.0 & 4.2 & 3.3 & 2.8 & 5.0 & 3.6 & 2.3 & 1.8 & 1.2 \\
\hline Depth $(\mathrm{m})$ & 1.2 & 1.2 & 1.0 & 0.9 & 1.2 & 1.1 & 1.0 & 0.9 & 0.7 \\
\hline Mean velocity $(\mathrm{m} / \mathrm{s})$ & 1.00 & 0.83 & 0.83 & 0.80 & 1.00 & 0.80 & 0.61 & 0.51 & 0.46 \\
\hline
\end{tabular}
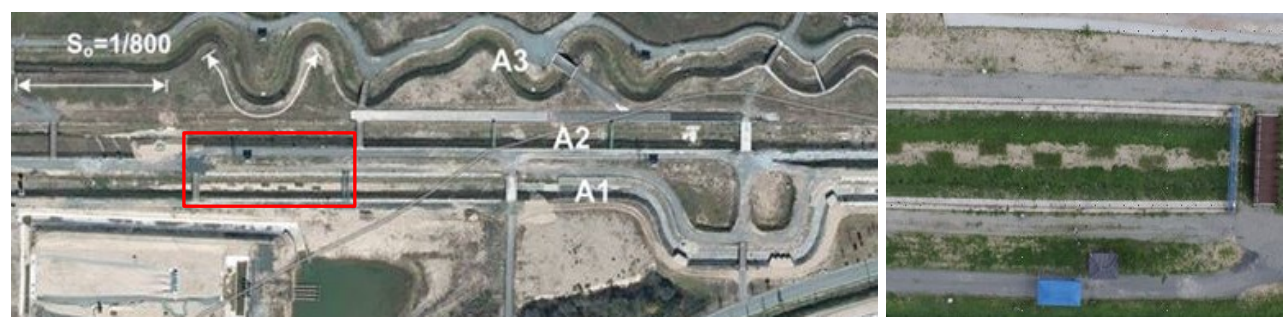

Fig. 1. KICT-REC Large-scale outdoor flumes (left photo) and red box indicates vegetation patches shown in the right photo (Flow direction $\leftarrow$ ). 


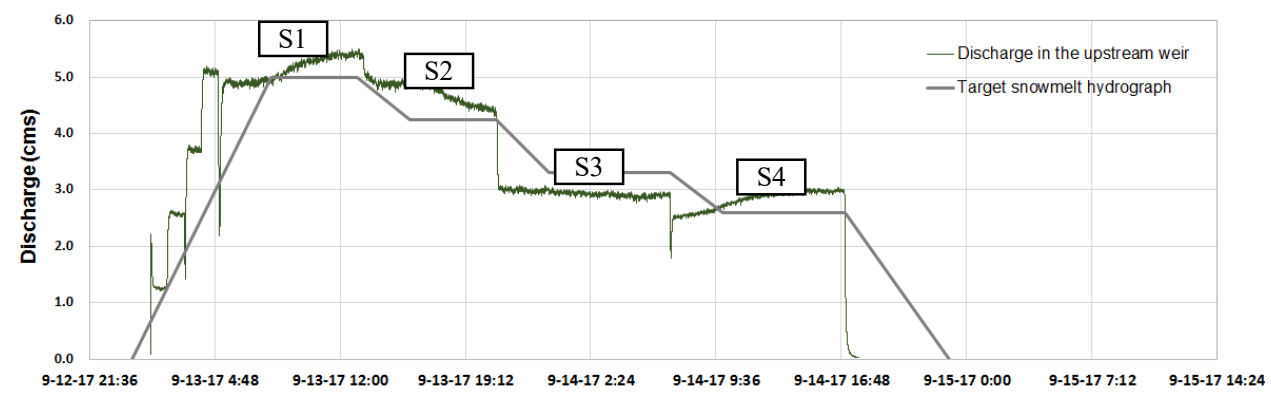

(a)

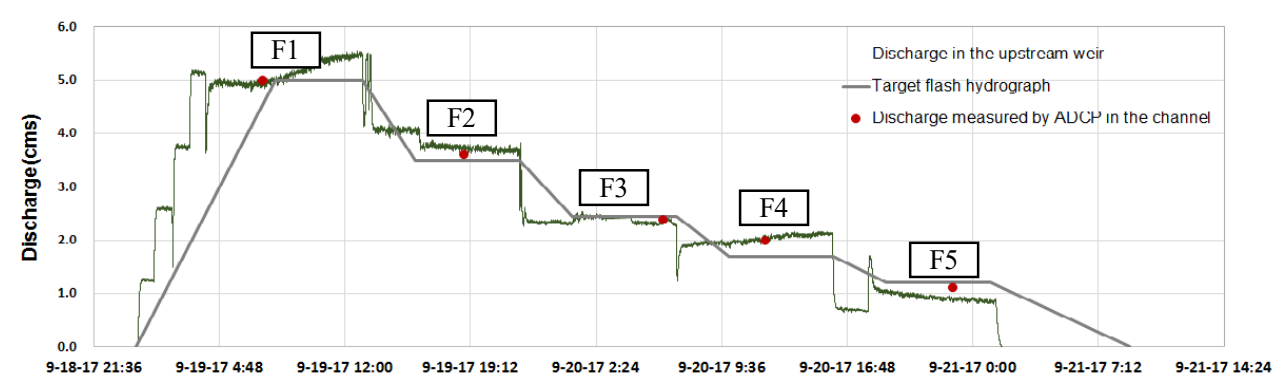

(b)

Fig. 2. Discharge variations for (a) snowmelt hydrograph and (b) flash flood hydrograph

Velocity measurement were made at three different cross-sections of D0, D2 and D4 (Fig. 3). D0 section represents flow at an approaching cross-section without any vegetation effects. D2 locates at very middle of the first vegetation patch. Inside the patch there are three horizontal velocity measuring points (P2-P4). P1 and P5 represent boundary between the patch and free flowing water and others (P0, P6-P9) for free flow. Cross-section D4 means flow behind the vegetation patch. For D0 and D4 section, velocity was measured at horizontally 7 and vertically 3 points, while for D2 section measurement was made at 5 vertical points. $50-\mathrm{Hz}$ Sontek Micro-ADVs and the same frequency Nortek Vectrino ADVs are used to measure point velocities at least 60 seconds for every location.

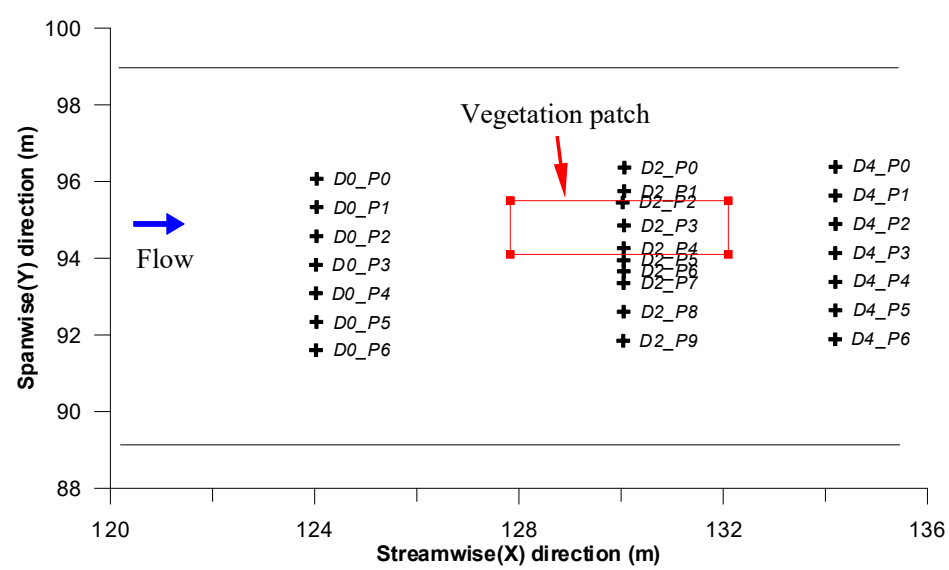

Fig. 3. Velocity measuring points at three sections (upstream, middle and downstream of the first vegetation patch). 


\section{Results and discussions}

\subsection{Horizontal flow characteristics}

Horizontally distributed depth-averaged streamwise velocity is shown in Fig. 4 with a base aerial photograph taken during the experiment. At the approaching section (D0), velocity shows nearly uniform distribution in transverse direction. It seems to reflect trapezoidal shape of cross-section. At the mid-patch section (D2), velocity in the middle of the patch is retarded, but there is difference in relative amount of velocity reduction due to difference in discharge (mean velocity) and depth condition. Flow is accelerated along free flowing zone of both sides of the patch. D4 section indicates there is a low velocity zone downstream of the patch. Magnitude of velocity behind the patch is comparable to that in the middle of the patch and it means reacceleration which may be caused by dividing flow upstream of the second patch does not occur. This phenomenon shows that in terms of depth-averaged flow there is velocity retardation rather than recirculation behind the patch where flow can penetrate through the patch, and it is also confirmed with LSPIV result (Fig. 5).

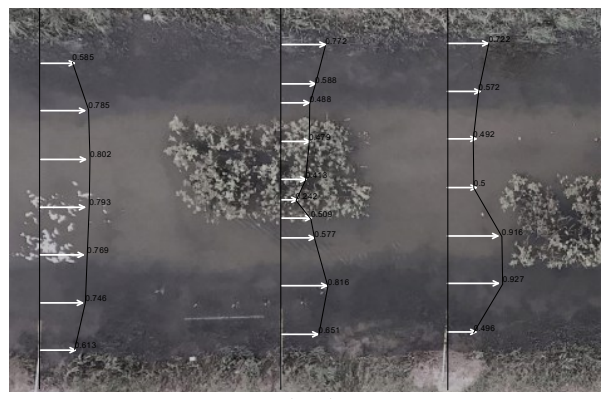

(S1)

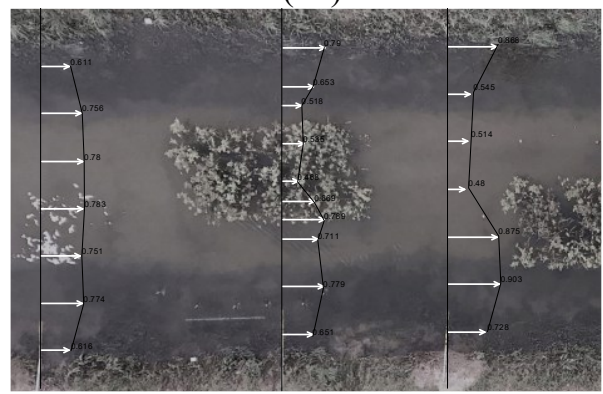

(F1)

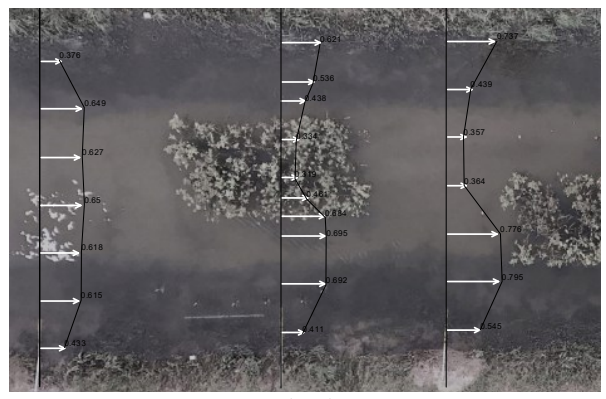

(S3)

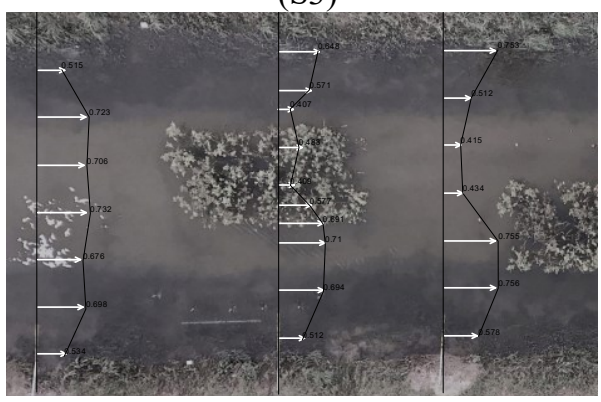

(F3)

Fig. 4. Depth-averaged velocity in horizontal plane with an aerial photo near the first vegetation patch.

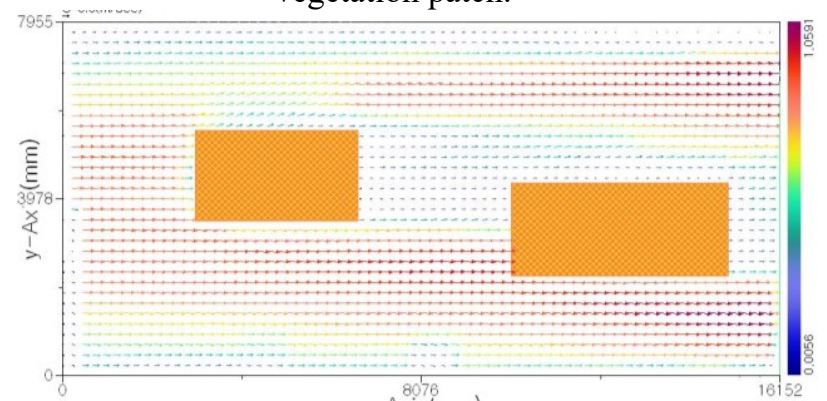

Fig. 5. Surface velocity vector measure with LSPIV for case F1 
During the experiment stems of willow trees trembled, while branches limitedly streamlined in response to the flow. It is because stems are rigid, while branches with many leaves are easily affected by flow forcing.

\subsection{Vertical velocity characteristics}

Fig. 6 shows depth and vertical profiles of mean longitudinal velocity at different points of each section for F1, F3 and F5. Velocities were measured at three $(0.25 / 0.5 / 0.75 \mathrm{~d}$ from the surface) for D0 and D4 sections and five $(0.2 / 0.4 / 0.6 / 0.8 / 0.9 \mathrm{~d}$ from the surface) depth points for D2 sections in the vertical. At D0 section, vertical profiles nearly agree to typical upward increasing pattern. In contrast, vertical profiles at the cross-section D2 show different shapes. At points far from the vegetation patch (P0, P8, P9), vertical profiles show typical pattern with increasing velocity magnitude from F5 (lowest discharge) to F1 (highest discharge). At points inside the patch (P2, P3, P4), vertical profiles are distorted due to vegetation. Velocity increases with increasing distance from bed, but vertical points near and above the canopy start height, velocity is slowed down compared to the points located just below. It indicates flow through the canopy leaf layer suffers more from local retardation. Vertical profile adjacent the patch such as P1, P5 and P6 also shows weak reverse pattern along with P1-P3 at the D4 section. This means that penetrating flow occurs at relatively lower level where resistance due to willow leaves exerts less effect and there is vertical separation between these layers.
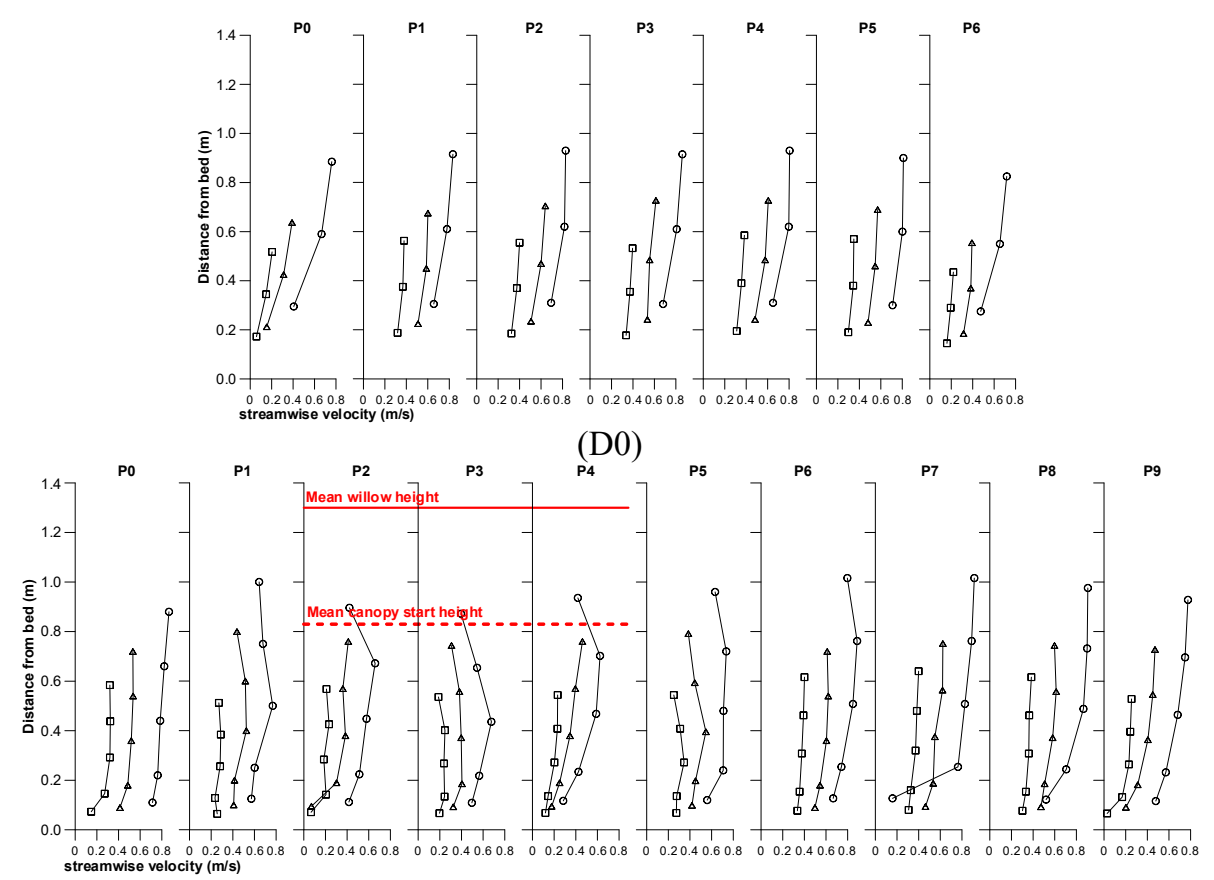

(D2) 


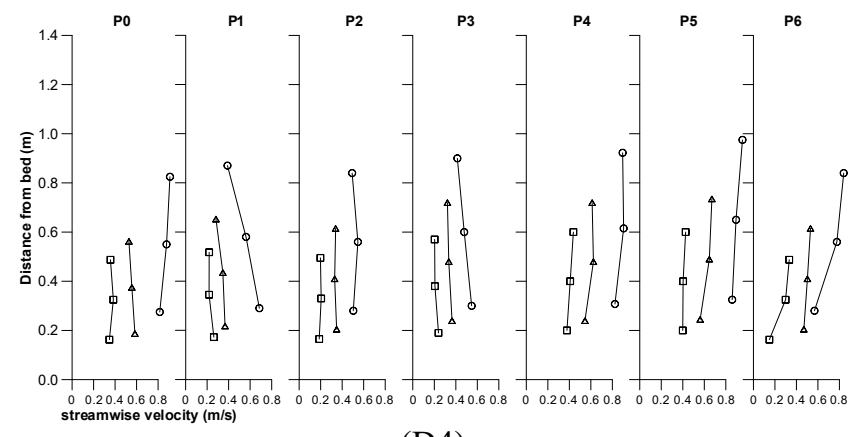

(D4)

Fig. 6. Depth and vertical velocity profiles at each measuring point for each cross-section for F1(circles), F3(triangles) and F5(boxes) cases.

\section{Summary and conclusions}

In this paper, we present some velocity measurement result near an actual willow patch along the real-sized experiment flume of KICT-REC. The result indicates that a vegetation patch retards flow, but there is still penetration rather than separation in the lee side of the patch. Though the depth of the experiment did not come to submergence of a willow patch, we found that effect of leaf canopy causes vertical flow separation between a canopy and a stem layers. The results of the experiment may help to enhance understanding on interaction of flow and actual vegetation in a natural channel and also evaluate flow resistance used for hydrodynamic modeling and validation.

\section{Acknowledgement}

This research is supported by Korea Institute of Construction Technology (Project name: River Experiment Center Management Project) and the National Research Foundation of Korea (NRF) grant funded by the Korea government (MSIP)(No.2017R1A2B4007131).

\section{References}

1. B. Räpple, H. Piégay, J.C. Stella, D. Mercier, Ecohydrology, 10 (2017)

2. A.M. Gurnell, G.E. Petts, Ear. Surf. Proc. Land. 31, 1558-1574. (2006)

3. T. Uotani, K. Kanda, K. Michioku, 2014, J. of Hydrodyn. Ser. B, 26, 796-806 (2014)

4. L. Zong, H. Nepf, Geomorph. 116, 363-372 (2010)

5. J. Cui, V.S. Neary, J. of Hyd. Res. 46, 307-316 (2008)

6. J. Järvelä, J. of Hyd. 269, 44-54 (2002) 